Alma Mater Studiorum - Università di Bologna DEPARTMENT OF ECONOMICS

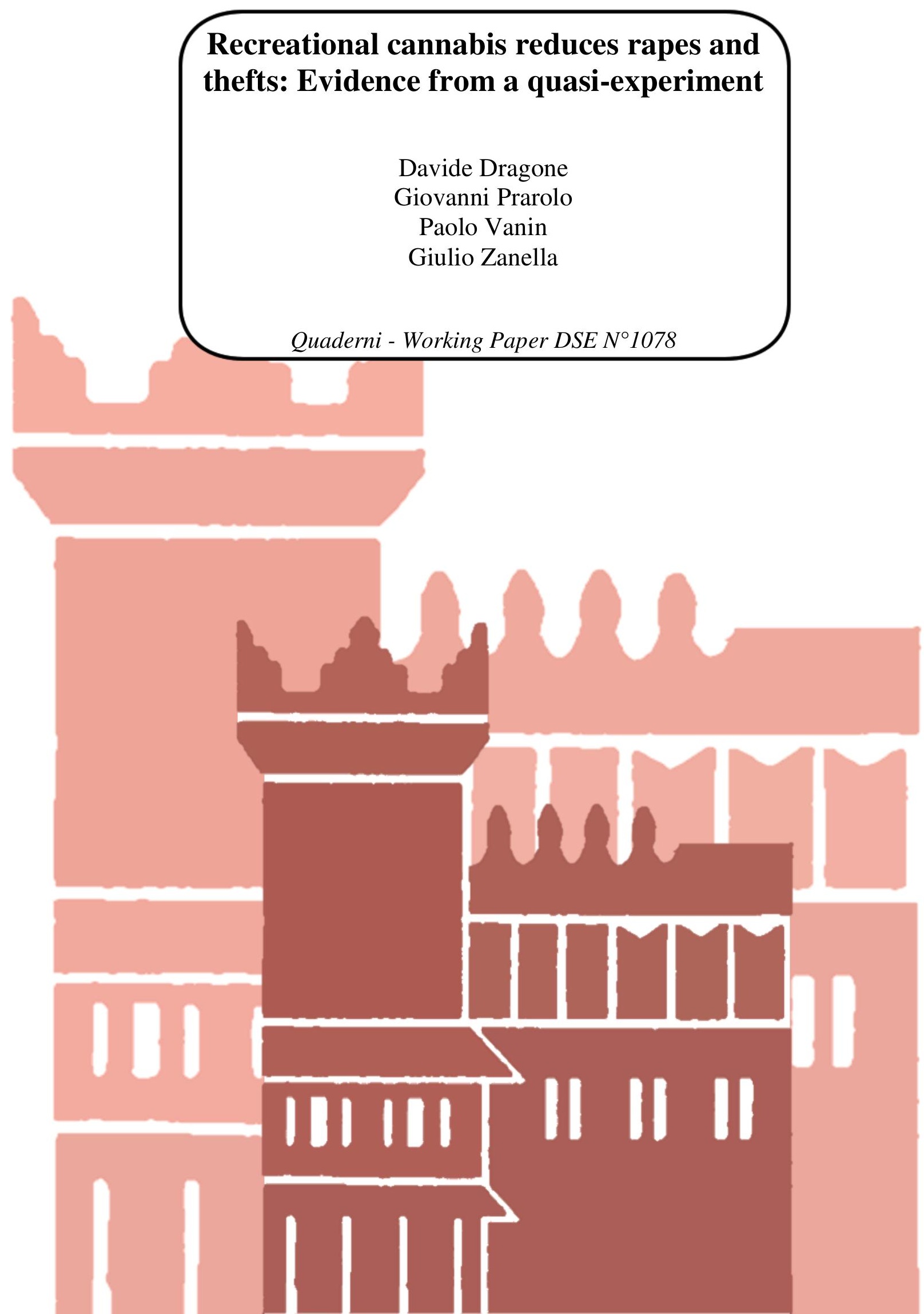




\title{
Recreational cannabis reduces rapes and thefts: Evidence from a quasi-experiment
}

\author{
Davide Dragone, ${ }^{\star \dagger}$ Giovanni Prarolo, ${ }^{\star \dagger}$ Paolo Vanin, ${ }^{\star \dagger}$ Giulio Zanella ${ }^{\star \dagger}$ \\ ^Department of Economics, University of Bologna, \\ Piazza Scaravilli 2, 40126 Bologna BO, Italy \\ ${ }^{\dagger}$ To whom correspondence should be addressed:
}

davide.dragone@unibo.it, giovanni.prarolo@unibo.it,paolo.vanin@unibo.it, giulio.zanella@unibo.it.

September 19, 2016

\begin{abstract}
An argument against the legalization of the cannabis market is that such a policy would increase crime. Exploiting the recent staggered legalization enacted by the states of Washington (end of 2012) and Oregon (end of 2014) we show, combining difference-in-differences and spatial regression discontinuity designs, that recreational cannabis caused a significant reduction of rapes and thefts on the Washington side of the border in 2013-2014 relative to the Oregon side and relative to the pre-legalization years 2010-2012.
\end{abstract}

Keywords: cannabis, recreational marijuana, crime

JEL codes: K23, K42

The presumption that drugs and crime are causally related is a major argument in support of a prohibitionist approach to substance use. Three possible reasons have been suggested for why illicit drug use may increase crime (Goldstein, 1985): psychopharmacological effects (the "reefer madness"), stealing to buy expensive drugs, and drug wars within the system of drug distribution. Such concerns are at center stage in the current debate about whether restrictions to cannabis sale and use should be relaxed or not. The legalization and liberalization of the cannabis market may shut down the drug wars channel and reduce prices, but it may exacerbate the psychopharmacological channel. According to the California Police Chiefs Association 
(2009), "public officials and criminal justice organizations who oppose medical marijuana laws often cite the prospect of increased crime". Supporting this presumption, case studies of crime reports found drugs to be a contributing factor (Goldstein, 1985), and it has been observed that a higher percentage of persons arrested test positive for illicit drugs compared with the general population (US Department of Justice). Yet, research on the recent wave of legalization of cannabis for medical use ("medical marijuana laws", MML henceforth) in the US yields mixed results on the association between illicit drug use and crime. Some researchers find no significant relationship between MML and crime (Keppler and Freisthler, 2012; Braakman and Jones, 2014; Morris et al., 2014; Freisthler et al., 2016; Shepard and Blackley, 2016), while others show that MML may reduce some kind of non-drug crimes either because of reduced activity by drug-trafficking organizations (Gavrilova et al., 2014) or because the police reallocates effort away from drug-related crimes and towards other types of offenses (Adda et al., 2014).

The estimation of a causal effect going from legalizing cannabis to crime rates remains an elusive question because of the lack of an experimental design (Miron, 2004). The present research takes advantage of the full legalization of the market for marijuana that recently took place in Washington (WA) and Oregon (OR), to engineer a quasi-experiment able to provide first-pass causal evidence on the relationship between recreational cannabis and crime rates. The WA-OR comparison offers an experimental opportunity because these are neighboring (hence similar, in many respects) states that legalized cannabis for recreational use (the strongest form of legalization) at about the same time, but with a time lag that induces a quasi-experiment. At the general election ballot of November 2012, voters in the state of WA approved with about $56 \%$ of votes Initiative 502, which allows producing, processing, and selling cannabis, subject to licensing and regulation by the Liquor Control Board, allows limited possession by persons aged 21 and over (but not home cultivation), and taxes sales. Legal possession began on December 9, 2012. Regulations for producers, processors and sellers were approved in 2013 and retail sales of recreational cannabis began July, 82014 (Darnell, 2015). Shortly after, the state of OR passed a similar reform. At the November 2014 general election ballot, voters in OR approved with about $56 \%$ of votes Measure 91, a cannabis law reform that is similar to the one passed in WA in terms of taxing sales and subjecting them to regulation and licensing by the Liquor Control Commission, but is more permissive in terms of possession and cultivation. ${ }^{1}$ A previous legalization attempt in OR (Measure 80 of 2012), quite permissive in terms of regulation and oversight, was marginally rejected with around $53 \%$ of votes in November 2012, thus enhancing the comparability with WA. Legalization of possession, use and home cultivation started in OR in July 2015, recreational sales through medical dispensaries in October 2015, and retail store licenses are scheduled to begin in October 2016. Therefore, the timing of the reforms was such that cannabis was legal on one side of the border two years before the other side. Specifically, in 2013 and 2014 cannabis was legal in WA but not in OR, a temporary 2-year window followed

\footnotetext{
${ }^{1}$ Home cultivation of up to four plants per household is allowed. Adults over the age of 21 are allowed to carry 1 ounce and keep 8 ounces at home, whereas WA establishes a possession limit of 1 ounce.
} 
by a virtually identical legal status across the border between two similar states where voters had a similar attitude towards legalizing cannabis. This allows us to combine a differencein-differences (DID) design (where WA acts as the treatment group, OR as the control group, 2010-2012 is the pre-legalization period and 2013-2014 is the post-legalization period) and a spatial regression discontinuity (SRD) design (where the WA-OR border marks a discontinuity in the legal status of cannabis in 2013-2014) to identify the causal impact of legal cannabis on violent and property crime.

We employ data on criminal activity at the county level from the US Uniform Crime Reporting (UCR) statistics, available at http://www.ucrdatatool.gov/. The data base contains the number of offenses reported by the sheriff's office or county police department. For the reasons detailed in the Supplementary Materials, these are not necessarily the county totals, but they are the only publicly available information from the UCR at the county level of disaggregation. We collected these crime data for years 2010 to 2014. For each county and each year, we have the total number of reported offenses for murder, rape, assault, robbery, burglary, and theft. The final dataset is an unbalanced panel (since not all counties report crime data every year) consisting of 335 observations for 75 counties, 36 in OR and 39 in WA. County-level population from the 2010 Census is used to obtain crime rates per 100,000 inhabitants. The distance of each county's centroid from the WA-OR border is computed using a GIS software. Four features of our data are crucial for identification. First, WA and OR share similar geographic, economic and institutional characteristics, including (quite crucially) a similar attitude towards legal cannabis. Second, WA legalized the cannabis market at the end of 2012, and OR (despite an attempt to legalize it in that same year) in 2014, which results in a 2-year period in which recreational cannabis is legal on one side of the border and illegal on the other side. Third, the longitudinal dimension of the data allows us to condition on county fixed effects and time effects, thus netting out unobserved local characteristics that do not change over time, as well as those factors that vary over time but are common to all counties. Fourth, the geographical features of the data allow us to identify the effect of the policy at the WA-OR border, where treated and control counties offer a better comparison: arguably, the similarity between two different states is maximized when comparing bordering counties. Moreover, by conditioning on distance from the border and by allowing for different effects of the spatial gap before and after the legalization, the SRD design controls for the effect of distance from the border on crime rates, including possible spillovers due to cross-border activity in response to the different legal status of cannabis. A potential confounding factor is that other relevant legal or institutional changes affecting crime rates in WA may have taken place in 2013-2014. As detailed in the Supplementary Materials, there is no evidence of such changes. We also show in the Supplementary Materials that our results do not change if we exclude the 5 counties in WA where cannabis business is prohibited and where according to the WA Liquor Control Board, Marijuana Sales Activity by License Number, no recreational cannabis retailers are present. These are Columbia, Franklin, Garfield, Wahkiakum, and Walla Walla County, all of them bordering Oregon except Franklin County. Preliminary graphical evidence is offered in Figure 1. The 
Figure 1: Variation in crime between before and after the WA legalization
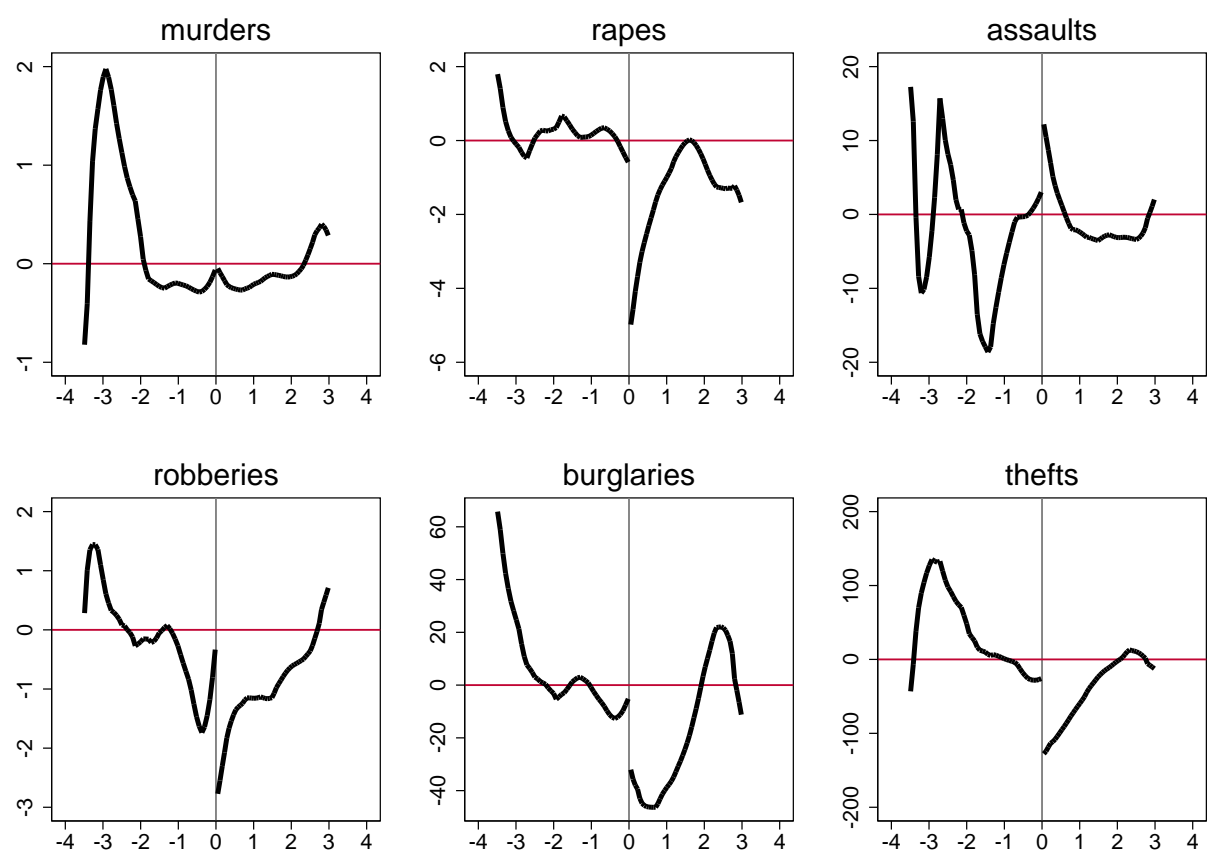

Notes: The figure shows the variation in county-level crimes per 100k inhabitants (vertical axis) as a function of the distance of the county centroid from the OR-WA border measured in hundreds of kilometers (horizontal axis). A positive distance means that the county is located in WA, and a negative distance means that the county is located in OR. The jump at zero distance is a non-parametric DID-SRD estimate of the effect of the legalization policy. The lines are smoothed county-level differences in crime rates obtained from local linear regressions, weighted by county population, employing a triangular kernel and a bandwidth of 100 kilometers.

figure plots nonparametric estimates of the difference between county-level crime rates before (2010-2012) and after (2013-2014) the WA legalization, as a function of the distance (measured in hundreds of kilometers) of the county centroid from the WA-OR border. In each panel of Figure 1, the difference between the variations in crime rates at the border (i.e., the jump at zero distance) is therefore a nonparametric estimate of the effect of legalizing cannabis. Except for murders (for which the variation is essentially zero on both sides of the border) and assaults, the drop in crime on the WA side of the border is much larger than the corresponding drop on the OR side.

To provide a more formal statistical analysis, we employ a parametric model that allows us to condition on unobserved county and time effects. Let $c_{i t}$ be the crime rate in county $i$ and year $t$, and define the following binary variables: first, $w_{i}=1$ if county $i$ is located in WA (treatment), and $w_{i}=0$ if county $i$ is located in OR (control); second, $p_{t}=1$ if year $t>2012$ (post), and $p_{t}=0$ if year $t \leq 2012$ (pre). The DID-SRD design, sometimes referred to as the Differencein-Spatial-Discontinuity design (Dickert-Conlin and Elder, 2010; Gagliarducci and Nannicini , 
Table 1: Difference in Discontinuity estimates of the effect of recreational cannabis on crime

\begin{tabular}{lcccccc}
\hline & Murder & Rape & Assault & Robbery & Burglary & Theft \\
\hline Estimated $\beta$ & 0.23 & $-4.21^{* *}$ & -1.30 & -1.26 & -36.32 & $-105.62^{*}$ \\
& $(0.45)$ & $(1.26)$ & $(8.79)$ & $(1.92)$ & $(22.20)$ & $(40.21)$ \\
Observations & 335 & 335 & 335 & 335 & 335 & 335 \\
\hline
\end{tabular}

Notes: The table reports estimates of $\beta$ from OLS on Equation 1, a coefficient that represents the difference in the spatial regression discontinuity estimates between the pre and post periods, i.e., by how much liberalizing recreational cannabis in WA changed the difference in crime rates right across the WA-OR border. Heteroskedasticityrobust standard error are reported in parentheses, and are clustered at the county level. Each county is weighted in the regression based on the size of its population in the 2010 Census. Significance level: * 5\%; ** $1 \%$ or better.

2013) can be represented by the following model:

$$
c_{i t}=k+\alpha p_{t}+\beta w_{i} p_{t}+f\left(d_{i}\right) p_{t}+g\left(d_{i}\right) w_{i} p_{t}+\theta_{i}+\xi_{i t},
$$

where $k$ is a constant, $f($.$) and g($.$) are polynomials of the same order (but possibly different$ coefficients) in distance, $\theta_{i}$ are county fixed effects, and $\xi_{i t}$ are residual determinants of crime. Coefficient $\beta$ is the difference in the SRD estimates between the pre and post periods, i.e., by how much liberalizing recreational cannabis in WA changed the difference in crime rates right across the WA-OR border. We estimated in Equation 1 by Ordinary Least Squares (OLS), employing quadratic polynomials in distance as is appropriate in a parametric framework (Gelman and Imbens, 2014). The resulting estimates of $\beta$ are reported in Table 1 . There is no evidence that the legalization of recreational cannabis enacted in WA caused an increase in crime rates. There is instead evidence of the contrary: the point estimates for rape, assault, robbery, burglary and theft are all negative, indicating that legalizing recreational cannabis has actually reduced crime in WA. This conclusion is reinforced by the statistical significance of the drop in rapes $(\mathrm{p}$-value $=0.001)$ and thefts ( $\mathrm{p}$-value $=0.01)$. For rapes, the reduction is 4.2 offenses per 100,000 inhabitants, which is about $30 \%$ of the 2010-2012 rate. For thefts, the reduction is 105.6 offenses per 100,000 inhabitants, which is about $20 \%$ of the $2010-2012$ rate. Note that the parametric estimates of $\beta$ in Table 1 are in the same ballpark of the jump at zero-distance in Figure 1 (except for burglaries). This indicates that our parametric choices are not driving the results. 
In conclusion, the WA-OR quasi-experiment provides first-pass evidence that legalizing cannabis may well cause a drop in crime. This result can be due to different, but possibly complementary, mechanisms. First, a fully legalized market for cannabis reduces involvement by drugtrafficking criminal organizations. Second, it allows the police to divert resources toward preventing non-cannabis related crimes. This effect is reinforced if cannabis dispensaries adopt security measures. Third, cannabis use determines a variety of psychoactive effects, which include a state of relaxation and euphoria (Hall et al., 2001; Green et al, 2003), and may thus reduce the likelihood of engaging in violent activities. This would hold, in particular, if cannabis is a substitute for violence-inducing substances such as alcohol, cocaine and amphetamines (DiNardo and Lemieux, 2001; Williams et al., 2004). These hypotheses are consistent with recent results obtained by exploiting the recent enactment MML's (Keppler, and Freisthler, 2012; Morris et al., 2014; Freisthler et al., 2016; Gavrilova et al., 2016; Shepard and Blackley, 2016), but further research is needed to disentangle the relative importance of different channels. 


\section{References and notes}

Adda, Jérôme, McConnell, Brendon, and Rasul, Imran (2014). Crime and the depenalization of cannabis possession: Evidence from a policing experiment. Journal of Political Economy 122(5), 1130-1202.

Braakman, Nils, and Jones, Simon (2014). Cannabis depenalisation, drug consumption and crime: Evidence from the 2004 cannabis declassification in the UK. Social Science \& Medicine 115, 29-37.

Darnell, Adam J (2015). I-502 evaluation plan and preliminary report on implementation (Document Number 1509-3201). Olympia: Washington State Institute for Public Policy. Retrieved from http://www.wsipp.wa.gov/ReportFile/1616/Wsipp_I-502-Evaluation-Plan-and-Preliminary-Report-onImplementation_Report.pdf (accessed 27 August 2016).

Dickert-Conlin, S., and T. Elder (2010). Suburban Legend: School Cutoff Dates and the Timing of Births. Economics of Education Review, 29, 826-841.

DiNardo, John, and Lemieux, Thomas (2001). Alcohol, marijuana, and American youth: the unintended consequences of government regulation. Journal of Health Economics 20(6), 991-1010.

Freisthler, Bridget, Ponicki, William R., Gaidus, Andrew, and Gruenewald, Paul J. (2016). A microtemporal geospatial analysis of medical marijuana dispensaries and crime in Long Beach, California. Addiction 111(6), 1027-1035.

Gagliarducci, S., and T. Nannicini (2013). Do Better Paid Politicians Perform Better? Disentangling Incentives from Selection. Journal of the European Economic Association, 11, 369-398.

Gavrilova, Evelina, Kamada, Takuma, and Zoutman, Floris T (2014). Is legal pot crippling Mexican drug trafficking organizations? The effect of medical marijuana laws on US crime. Discussion Paper. Institutt for Foretaksokinimi, Department of Business and Management Science.

Gelman, A, and G. Imbens (2014). Why High-order Polynomials Should not be Used in Regression Discontinuity Designs. NBER Working Papers 20405, National Bureau of Economic Research, Inc.

Goldstein, Paul J (1985). The drugs/violence nexus: A tripartite conceptual framework. Journal of Drug Issues 15(4), 493-506.

Green, Bob, Kavanagh, David, and Young, Ross (2003). Being stoned: a review of self-reported cannabis effects. Drug and Alcohol Review 22(4), 453-460.

Hall, Wayne, Degenhardt, Louisa, and Lynskey, Michael (2001). The health and psychological effects of cannabis use. National Drug and Alcohol Research Centre, Monograph Series 44.

Keppler, Nancy J, and Freisthler, Bridget (2012). Exploring the ecological association between crime and medical marijuana dispensaries. Journal of Studies on Alcohol and Drugs 73(4), 523-530.

Miron, Jeffrey A (2004). Drug war crimes: The consequences of prohibition. Oakland, CA: The Independent Institute. 
Morris, Robert G, TenEyck, Michael, Barnes, James C, and Kovandzic, Tomislav V (2014). The effect of medical marijuana laws on crime: evidence from state panel data 1990-2006. PloS One 9(3), e92816.

Shepard, Edward M, and Blackley, Paul R (2016). Medical marijuana and crime: Further evidence from the western states. Journal of Drug Issues 46(2), 122-134.

Williams, Jenny, Pacula, Rosalie Liccardo, Chaloupka, Frank J. and Wechsler, Henry (2004). Alcohol and marijuana use among college students: economic complements or substitutes?. Health Economics 13(9), 825-843. 


\section{Supplementary Materials to "Evidence that legalized cannabis for recreational use has re- duced rapes and thefts in the state of Washington"}

These Supplementary Materials expand on crime rates, elaborate on the methodology, and present robustness checks.

Table 2 reports crime rates in WA and OR counties between 2010 and 2014: all counties at the top of the table, counties at the WA-OR border at the bottom. Because these rates result from the aggregation of county-level reports in the UCR, they do not necessarily coincide with state-level counts. The reason of the discrepancy is twofold, as explained by the FBI's Criminal Justice Information Services Division at http: / / www . ucrdatatool .gov/faq. cfm. First, "only data for city law enforcement agencies 10,000 and over in population and county law enforcement agencies 25,000 and over in population are on this site". That is, crimes occurring in smaller cities are not counted for the published county-level totals. Second, "Because not all law enforcement agencies provide data for complete reporting periods, it is necessary to estimate for the missing data" when building statistics beyond the county level of aggregation. That is, the FBI imputes crime counts to non-reporting agencies when building estimates at the state and nation levels.

The methodology we employ combines a Difference-in-Differences (DID) and a Spatial Regression Discontinuity (SRD) designs. The estimating equation is:

$$
c_{i t}=k+\alpha p_{t}+\beta w_{i} p_{t}+f\left(d_{i}\right) p_{t}+g\left(d_{i}\right) w_{i} p_{t}+\theta_{i}+\xi_{i t},
$$

where $c_{i t}$ is the crime rate in county $i$ and year $t, k$ is a constant, $w_{i}=1$ if county $i$ is located in WA (treatment), and $w_{i}=0$ if county $i$ is located in OR (control), $p_{t}=1$ if year $t>2012$

(post), $p_{t}=1$ if year $t \leq 2012$ (pre), and $f($.$) and g($.$) are polynomials of the same order (but$ possibly different coefficients) in distance, and $\theta_{i}$ are county fixed effects. Equation 1 results from the combination of two different designs widely used in applied econometrics. First, a 
DID design would be based on the linear regression model

$$
c_{i t}=k+\alpha p_{t}+\beta w_{i} p_{t}+\theta_{i}+\epsilon_{i t},
$$

where $\beta$ is the DID effect of the policy. A SRD design would restrict to $p_{t}=1$ and condition on distance from the border, thus leading to linear regression model

$$
c_{i t}=k+f\left(d_{i}\right)+g\left(d_{i}\right) w_{i}+\beta w_{i}+\varepsilon_{i t},
$$

where $\beta$ is now the SRD effect of the policy. Equation 1 results from combining Equation 3 and Equation 4. This is the sense in which $\beta$ in Equation 1 is the difference in the SRD estimates between the pre and post periods, i.e., by how much liberalizing recreational cannabis in WA changed the difference in crime rates right across the WA-OR border.

An analysis of legal or institutional changes taking place in WA in 2013-2014 reveals no relevant events that may have affected crime rates at the same time as the legalization of cannabis possession and use. During this period, a reorganization of the 911 emergency call system took place in WA, and there were reforms related to health services, regulation of wine and beer, and drug courts. There were also changes in the statute of limitations for child molestation, incest (victim under age eighteen), and rape (victim under age eighteen), as well as new norms concerning commercial sale of sex and commercial sexual abuse, sexually violent predators, and sexual violence at school. However, all of these changes were too marginal to exert a first-order effect on crime.

Finally, we re-estimate the DID-SRD model after excluding 5 WA counties where cannabis business is prohibited and where, according to the Liquor Control Board, Marijuana Sales Activity by License Number, no non-medical cannabis retailers are present. These are Columbia, Franklin, Garfield, Wahkiakum, and Walla Walla County, all of them bordering Oregon except Franklin County. Results are reported in Table 3. These confirm negative point estimates for all of the categories considered, and significant drops in rapes and thefts. 
Table 2: Crime rates at the county level

\begin{tabular}{ccccccc}
\hline Year & Murder & Rape & Assault & Robbery & Burglary & Theft \\
\hline \multicolumn{7}{c}{ All WA counties $(N=39)$} \\
2010 & 0.76 & 10.96 & 46.66 & 12.17 & 265.79 & 458.97 \\
2011 & 0.85 & 9.65 & 40.84 & 10.30 & 265.08 & 440.87 \\
2012 & 1.03 & 9.16 & 42.70 & 9.99 & 287.77 & 432.55 \\
2013 & 0.80 & 9.07 & 41.23 & 9.21 & 258.73 & 419.59 \\
2014 & 0.73 & 9.70 & 41.21 & 10.47 & 246.90 & 399.60 \\
\hline
\end{tabular}

All OR counties $(N=36)$

\begin{tabular}{lllllll}
2010 & 0.80 & 7.22 & 34.31 & 6.82 & 132.96 & 393.71 \\
2011 & 0.66 & 7.26 & 32.02 & 6.26 & 142.14 & 387.37 \\
2012 & 0.84 & 7.51 & 29.31 & 6.75 & 150.93 & 412.93 \\
2013 & 0.88 & 5.69 & 22.48 & 5.40 & 146.14 & 433.22 \\
2014 & 0.66 & 7.22 & 30.21 & 4.72 & 115.17 & 335.12 \\
\hline
\end{tabular}

Border WA counties $(N=11)$

\begin{tabular}{lllllll}
2010 & 0.35 & 15.37 & 33.69 & 8.51 & 224.00 & 529.80 \\
2011 & 0.48 & 13.56 & 33.55 & 9.69 & 212.19 & 491.00 \\
2012 & 0.75 & 12.80 & 42.00 & 7.58 & 223.30 & 445.11 \\
2013 & 0.59 & 10.28 & 40.78 & 6.15 & 210.41 & 407.93 \\
2014 & 0.71 & 10.52 & 39.48 & 6.97 & 184.76 & 357.10 \\
\hline
\end{tabular}

Border OR counties $(N=10)$

\begin{tabular}{lllllll}
2010 & 0.34 & 1.58 & 13.40 & 3.04 & 41.88 & 163.57 \\
2011 & 0.44 & 2.51 & 11.22 & 1.31 & 49.15 & 158.78 \\
2012 & 0.31 & 2.59 & 10.76 & 1.14 & 56.88 & 176.11 \\
2013 & 0.10 & 1.77 & 11.67 & 1.67 & 41.04 & 144.27 \\
2014 & 0.11 & 0.91 & 14.89 & 2.39 & 40.91 & 128.08 \\
\hline
\end{tabular}

Notes: Average crimes per 100,000 inhabitants in WA and OR counties, estimated from the county-level counts reported in the Uniform Crime Reporting Statistics. The averages are weighted by county population. 
Table 3: Difference in Discontinuity estimates of the effect of recreational cannabis on crime: robustness check

\begin{tabular}{lcccccc}
\hline & Murder & Rape & Assault & Robbery & Burglary & Theft \\
\hline Estimated $\beta$ & 0.20 & $-3.77 * *$ & -0.36 & -1.19 & -41.84 & $-117.51^{* *}$ \\
& $(0.49)$ & $(1.49)$ & $(9.14)$ & $(2.04)$ & $(25.40)$ & $(39.67)$ \\
Observations & 310 & 310 & 310 & 310 & 310 & 310 \\
\hline
\end{tabular}

Notes: The table reports estimates of $\beta$ from OLS on Equation 1, a coefficient that represents the difference in the spatial regression discontinuity estimates between the pre and post periods, i.e., by how much liberalizing recreational cannabis in WA changed the difference in crime rates right across the WA-OR border. WA counties are excluded were cannabis business is prohibited and where, according to the Liquor Control Board, Marijuana Sales Activity by License Number, no non-medical cannabis retailers are present. These are Columbia, Franklin, Garfield, Wahkiakum, and Walla Walla County, all of them bordering Oregon except Franklin County. Heteroskedasticity-robust standard error are reported in parentheses, and are clustered at the county level. Each county is weighted in the regression based on the size of its population in the 2010 Census. Significance level: * $5 \% ; * * 1 \%$ or better. 


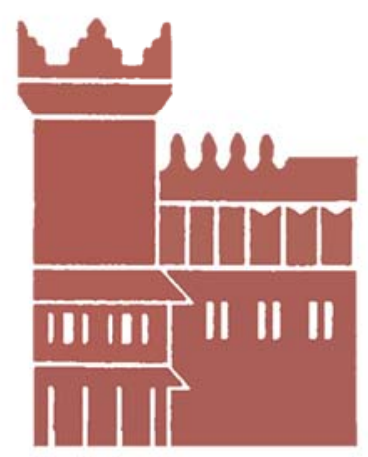

Alma Mater Studiorum - Università di Bologna DEPARTMENT OF ECONOMICS

Strada Maggiore 45

40125 Bologna - Italy

Tel. +39051 2092604

Fax +390512092664

http://www.dse.unibo.it 